\title{
PERLINDUNGAN PRIVASI DAN DATA PRIBADI KONSUMEN DARING PADA ONLINE MARKETPLACE SYSTEM
}

\author{
Masitoh Indriyani, Nilam Andaria Kusuma Sari, Satria Unggul W.P. \\ Fakultas Hukum Universitas Airlangga \\ Jl. Dharmawangsa Dalam Selatan, Airlangga, Gubeng, Kota Surabaya, Jawa Timur 60286 \\ Telp/Fax: (0623) 15023151, e-mail: masitoh@fh.unair.ac.id
}

\begin{abstract}
Abstrak
Online marketplace system merupakan satu diantara bentuk perkembangan aktifitas ecommerce. Online marketplace system menyediakan sarana aktifitas belanja secara daring dimana memuat berbagai layanan untuk mempermudah konsumen daring (e-consumer). Disisi lain, layanan yang mempermudah tersebut terdapat memberikan potensi ancaman bagi konsumen daring terutama terkait dengan data pribadi dan privasi konsumen daring tersebut. Penelitian ini membahas tentang perlindungan data pribadi dan privasi e-consumer pada online marketplace system dengan menggunakan metode penelitian normatif (legal research). Pendekatan penelitian yang digunakan adalah Statute Approach, Conceptual Approach, Case Approach serta Comparative Approach. Hasil dari penelitian ini tampak bahwa perkembangan e-commerce di Indonesia telah berjalan sedemikian pesat, setidaknya Negara mendorong lahirnya start up baru yang dapat memanfaatkan pelbagai program, salah satunya adaalah "1000 technopreuner" serta ada program-program lainnya. Namun, hal tersebut tidak akan berjalan efektif tanpa adanya perlindungan hukum yang memadai, khususnya terkait hak privasi dari konsumen. Di dalam regulasi nasional saat ini terdapat UU Nomor 11 Tahun 2008 tentang ITE, PP Nomor 28 tahun 2012 tentang Penyelenggaraan Sistem dan Transaksi Elektronik. Dengan dua regulasi hukum tersebut Kemenkominfo dapat melakukan pendaftaran dan pendataan bagi pelaku usaha e-commerce melalui serangkaian proses profiling dan report databased agar konsumen terhindar dari penipuan yang dilakukan oknum yang tidak bertanggungjawab
\end{abstract}

Kata kunci: perlindungan hukum, data pribadi, privasi, e-commerce, online marketplace system

\section{A. Pendahuluan}

Aktifitas belanja secara daring menjadi fenomena tersendiri di Indonesia. Data dan laporan yang dihimpun oleh the Wall Street Journal maupun We are Social menunjukkan peningkatan kegiatan daring yang sangat signifikan. Hal ini tak lepas dari banyaknya pengguna aktif internet yang memanfaatkan koneksi mobile internet untuk menjalankan aktivitas daringnya. Lembaga survei yang bergerak dalam isu tren global infrastruktur internet, We are Social, dalam laporannya menyatakan bahwa pada Januari 2015 pengguna internet aktif di seluruh dunia adalah sebesar 3 Milyar pengguna 
dengan prosentasi pertumbuhan sebesar $21 \% .^{1}$

Banyaknya angka pengguna internet di Indonesia menunjukkan potensi pasar yang besar yang akan mempengaruhi munculnya berbagai peluang bisnis baru. Disisi lain, ada beberapa hal yang perlu diperhatikan dalam kegiatan belanja daring adalah isu tentang perlindungan data pribadi dan para konsumen daring. Bahwa dalam aktifitas daring, data pribadi merupakan salah satu hal esensial terutama berkaitan dengan metode pembayaran, pemasaran dan penawaran.

Perusahaan e-comnmerce dalam menawarakan dan memasarkan barangnya bergantung kepada teknologi apa yang disebut sebagai ad-targeting. Ad-targeting adalah kegiatan yang dilakukan oleh kalangan industri dan bisnis untuk memasarkan sebuah produk barang dan jasa dengan cara menarget potential consumer. Latar belakang dari adtargeting sendiri adalah adanya teknologi yang memberikan kemudahan dan keakurasian dalam promosi dan pemasaran dengan biaya rendah. ${ }^{2}$

\footnotetext{
${ }^{1}$ Simon Kemp, (2015), Digital, Social, Mobile in 2015, We Are Social, http://wearesocial.sg/blog/2015/01/digital-socialmobile-2015/ [Akses 5 Juni 2017].

${ }^{2}$ Masitoh Indriani, (2015), Praktek Surveillance dan Unlawful Interception sebagai Pelanggaran terhadap Hak atas Privasi dalam Kebebasan
}

Dengan teknologi yang dipakai tersebut, terdapat potensi permasalahan pemanfaatan data pribadi para konsumen diantaranya pelacakan transaksi daring dimana didalamnya terdapat preferensi belanja, lokasi belanja, data komunikasi, hingga alamat seorang konsumen. Teknologi yang bernama cookies, ${ }^{3}$ dari perangkat tersebut mampu untuk merekam aktifitas pencarian kita dan hasilnya adalah ad targeting yang sesuai dengan hasil pencarian daring konsumen sebelumnya. Praktik intervensi terhadap privasi dan gangguan terhadap data pribadi tentunya menjadi salah satu persoalan besar yang mengemuka terutama dengan semakin meningkatnya pemanfaatan tekonologi informasi dan komunikasi seperti cookies dalam ad-targeting.

Situasi tersebut tentunya berakibat pada rentannya perlindungan hak atas privasi tiap-tiap konsumen daring. Diberbagai negara, isu yang terkait dengan privasi serta pengaturan mengenai privasi telah mulai berkembang sebagai bagian

Berekspresi di Indonesia: Hukum, Dinamika, Masalah dan Tantangannya, Jakarta: Elsam, hlm.192.

${ }^{3}$ Cookies adalah sekumpulan file kecil yang disimpan di dalam komputer seorang user. Cookies dirancang sedemikian rupa untuk menyimpan data spesiifik pada situs web tertentu sehingga dapat diakses balik oleh server website yang pernah dikunjungi. 
yang utuh dari perkembangan sosial masyarakatnya.

Bahkan, pengalaman di sejumlah negara demokratis menunjukan, hukum positif dan jurisprudensi mengenai privasi telah muncul jauh sebelum privasi menjadi bagian yang utuh dari rejim hukum hak asasi manusia internasional.

Dalam perkembangan terbaru, Dewan HAM PBB telah mengadopsi Resolusi 68/167 tentang perindungan hak atas privasi di era digital. ${ }^{4}$ Salah satu klausulnya menegaskan bahwa hak yang sama bagi setiap orang saat mereka offline juga harus dilindungi saat mereka online, termasuk hak atas privasi. Di Indonesia sendiri, isu mengenai pentingnya perlindungan hak atas privasi mulai menguat seiring dengan makin meningkatnya jumlah pengguna telepon seluler dan internet dalam beberapa tahun terakhir.

Berdasarkan laporan We are Social, Indonesia mencatat Sedangkan di Indonesia terdapat 72.7 juta pengguna aktif, 72 juta pengguna aktif media sosial dimana didalamnya terdapat 62 juta pengguna yang memanfaatkan mobile

\footnotetext{
${ }^{4}$ Tim Privacy International dan ELSAM, (2015), Privasi 101: Panduan Memahami Privasi, Perlindungan Data dan Surveilans Komunikasi, Jakarta: Elsam, hlm.5.
}

internet. $^{5}$ Sementara itu angka perilaku belanja daring di Indonesia pada Januari 2015 menunjukkan bahwa para konsumen daring ini lebuh memanfaatkan jaringan internet melalui Personal Compuer (PC) dan mobile internet dengan angka pengguna internet dengan perangkat $\mathrm{PC}$ adalah $18 \%$ dan perangkat mobile internet sebesar $16 \%{ }^{6}$ Indonesia sendiri, pada Maret 2016 mencatat angka pertumbuhan $16 \%$ terkait dengan aktivitas $e$ Commerce. $^{7}$ Sedangkan prosentase beberapa negara ASEAN misalnya Malaysia dengan angka pertumbuhan $37 \%$, Vietnam 24\%, Pilipina 21\%, dan Thailand $18 \% .^{8}$

Lebih lanjut, dalam laporannya The Wall Street Journal menyatakan bahwa berkembangnya aktifitas daring tersebut didukung oleh adanya akses terhadap infrastuktur jaringan internet. ${ }^{9}$ Sejumlah kasus yang mencuat, terutama yang memiliki keterkaitan dengan kebocoran

\footnotetext{
${ }^{5}$ Enrico Lukman, (2015), The latest numbers on web, mobile, and social media in Indonesia (INFOGRAPHIC, https://www.techinasia.com/indo nesia-web-mobile-data-start-2015, [akses pada 3 Maret 2017].

${ }^{6}$ Ibid.

${ }^{7}$ Simon Kemp, Op.Cit.

${ }^{8}$ Ibid.

9 Resty Woro Yuniar, (2015), What makes $e$ Commerce Work in Indonesia, The Wall Street Journal,http://blogs.wsj.com/indonesiarealtime/201 5/03/03/what-makes-e-commerce-work-inindonesia/, [akses pada 3 Maret 2017].
} 
data pribadi seseorang, yang berbuntut pada aksi penipuan, kian menguatkan wacana perihal urgensi penguatan perlindungan hak atas privasi. Dalam fakta keseharian, tidak adanya mekanisme perlindungan terhadap privasi, terutama data pribadi, berimbas pada penawaran kepada konsumen, bermacam produk, mulai dari properti, asuransi, fasilitas pinjaman,sampai dengan kartu kredit. Disisi lain konsumen sama sekali tidak pernah menyerahkan data pribadinya kepada produsen bersangkutan terkait dengan preferensi suatu produk maupun jasa.

Rumusan Masalah

Dari uraian latar belakang tersebut, rumusan masalah yang diangkat dalam penelitian ini adalah:

1. Pengaturan Privasi konsumen daring dalam online marketplace system.

2. Perlindungan Privasi dan Data Pribadi konsumen daring dalam online marketplace system.

\section{B. Metode Penelitian}

Penelitian normatif (legal research) dengan pendekatan statute approach, conceptual approach, case approach serta comparative approach.

\section{Pembahasan}

Definisi Online Marketplace System

Hukum ekonomi klasik telah memberi tanda terkait bagaimana sistem dan mekanisme perdagangan dijalankan, dimana jika ada permintaan (Supply), selalu ada penawaran (Demand), pun halnya terjadi didalam mekanisme $e$ commerce hari ini, yang dibutuhkan oleh penjual dan penyedia jasa e-commerce melihat peluang bahwa data privasi dari konsumen daring memberikan kemudahan untuk mengetahui dan menjual produkproduk sesuai yang diinginkan dengan tepat dan tanpa susah payah, walau hal tersebut jelas-jelas telah melanggar hak privasi dari konsumen daring itu sendiri.

Definisi online marketplace system menurut Albert J. Marcella Jr. dan Carol Stucki ${ }^{10}$ sebagai The collection and use of personal information for marketing purposes. Dalam istilah tersebut, dapat dilihat bahwa definisi terkait Online Markeplace System sebagai cara-cara mengkoleksi informasi pribadi secara daring untuk tujuan bisnis. selain melanggar hak privasi konsumen juga bentuk pengabaian prinsip-prinsip kepercayaan yang dibangun antara

\footnotetext{
${ }^{10}$ Albert J. Marcella Jr. dan Carol Stucki, (2003), Privacy Handbook: guidelines, exposures, policy implementation, and international issue, New Jersey: John Wiley \& Sons,Inc, hlm. 198.
} 
konsumen dengan penyedia jasa $e$ commerce yang dilakukan oleh penyedia platform online marketplace system.

Selanjutnya, teknologi cookies yang digunakan bagi penyedia platform online marketplace system untuk pengumpulan pelbagai macam preferensi pencarian produk seseorang tersebut digunakan sebagai basis pengetahuan dan minat dari calon pembeli dan pengetahuan bagi penyedia platform online marketplace system iklan-iklan mana yang cocok untuk dipasarkan dengan presisten kepada calon pembeli yang tepat, hal tersebut dapat diketahui melalui aksi-aksi yang dilakukan calon pembeli seperti: pengulangan akses terhadap suatu situs; interaksi; kata kunci; konten produk yang dicari secara online; dsb. setidaknya hal tersebut yang digambarkan oleh Rosemary Jane untuk mendefinisikan online marketplace system. $^{11}$

Online marketplace system menurut pandangan G.B.F.Niblett juga mengafirmasi pengertian yang sama, dimana dalam pengertiannya disebutkan sebagai penggunaan akses media online untuk memasuki hal-hal yang tidak diinginkan dari hak privasi inidividu yang

11 Rosemary Jay, (3rd edition), (2007), Data Protection: Law and Practices, Sweet \& Maxwell, London, hlm. 769-770. merupakan konsumen daring, hal tersebut bertujuan untuk kepentingan komersial dan industri sehingga calon konsumen adtargeted terhadap produk yang diminatinya. $^{12}$

Privacy Policy Dalam Online Marketplace System

Secara definisi, Anup K. Gosh menjabarkan Privacy Policy sebagai “... as a comprehensive description of a Web site's practices which is located in one place on the site and may be easily accessed. Every organization involved in electronic commerce transactions has a responsibility to adopt and implement a policy for protecting the privacy of individually identifiable information". ${ }^{13}$

$$
\text { Privacy policy merupakan }
$$
deskripsi yang lengkap yang menyatakan tentang tanggungjawab dan pelaksanaan dari ketentuan tersebut dalam rangka melindungi hak privasi seorang individu yang telah mengungkapkan data privasinya dalam kegiatan e-commerce. Privacy policy dalam setiap transaksi kegiatan $e$ commerce dapat diakses dengan mudah, hal ini dikarenakan ketentuan tersebut menjadi sangat penting dalam kegiatan $e$ -

${ }^{12}$ G.B.F.Niblett, (1992), Digital Informatian and Privacy Problem, Paris: OECD Publisher, hlm. 1617.

${ }^{13}$ Anup K. Ghos, (2001), E-commece Security and Privacy, Massachusetts: Kluwer Publishing, hlm. 71. 
commerce sebagai code of conduct yang dihormati oleh para pihak.

Pengaturan Privacy Policy Dalam Online Marketplace System Menurut Hukum Positif Indonesia

Indonesia secara umum memiliki regulasi hukum yang mengatur mengenai privacy policy dalam online marketplace system, yaitu terdapat dalam UndangUndang Nomor 11 tahun 2008 tentang Informasi dan Transaksi Elektronik (UU Nomor 18 Tahun 2008 tentang ITE) dan Peraturan Pemerintah Nomor 28 tahun 2012 tentang Penyelenggaraan Sistem dan Transaksi Elektronik (PP Nomor 28 Tahun 2012 tentang PSTE). Salah satu lead sector Pemerintah Indonesia yang menangani e-commerce adalah Kementerian Komunikasi dan Informasi (Kemenkominfo), ${ }^{14}$ dari dua regulasi hukum tersebut Kemenkominfo memiliki program pendaftaran dan pendataan bagi pelaku usaha e-commerce melalui serangkaian proses profiling dan report databased. Hal ini bertujuan agar konsumen terhindar dari penipuan yang dilakukan oknum yang tidak bertanggung jawab.

14 Hasil field research di Bidang Hukum Sub Direktorat E-Business, Kementerian Komunikasi dan Informasi RI, pada tanggal 21 Agustus 2016.
Kedepan, proyeksi perlindungan data privasi melalui mekanisme privacy policy pada online marketplace system terus berbenah, karena ada dua regulasi hukum yang secara spesifik mengatur mengenai hak privasi, yaitu Rancangan Peraturan Menteri tentang Perlindungan Data Pribadi yang meupakan amanah dari PP Nomor 82 tahun 2012 serta Rancangan UndangUndang mengenai Perlindungan Data Pribadi, dua regulasi hukum tersebut didorong oleh pemerintah untuk menjawab kebutuhan masyarakat terkait dengan perlindungan privasi konsumen. Tujuan dari regulasi hukum tersebut mendorong agar klausul baku yang sering disuguhkan kepada calon konsumen pada aplikasi $e$ commerce dapat secara adil dan terbuka untuk disepakati kedua belah pihak.

Kondisi riil dalam kegiatan $e$ commerce menunjukkan bahwa konsumen adalah pihak yang lemah dalam setiap transaksi tersebut, artinya aturan-aturan teknis terkait code of conduct dari aktivitas e-commerce tersebut diharapkan mampu melindungi kepentingan konsumen melalui detail per-consent dari privacy policy yang berlaku dalam setiap kegiatan e-commerce agar disepakati kedua belah pihak, sehingga penyedia platform online marketplace system tidak dengan mudah meng-collect data untuk profit oriented. 
Dalam konteks ini negara bersifat justice and fairness dalam menjadi "pihak ditengah-tengah" dan menjadi pihak yang mengkontrol privacy policy yang dirumuskan disepakati oleh penyedia jasa e-commerce/penjual dengan konsumen terkait dengan data privasi yang dilakukan secara daring. sehingga dalam konteks ini, klausul baku privacy policy yang sangat banyak kekurangan tersebut dapat segera diperbaiki agar hak-hak konsumen tidak terlanggar.

Pengaturan privacy policy Dalam Online Marketplace System di Beberapa Negara

Di beberapa negara khususnya di negara-negara anggota Uni Eropa dan Amerika Serikat yang telah established kondisi e-commerce yang ada telah mengatur mengenai mekanisme privacy policy dalam online marketplace system telah dituangkan didalam pelbagai regulasi hukum baik dalam aspek hukum internasional, tingkat regional (seperti $E U$ Directive) maupun dalam perundangundangan nasional.

Uni Eropa

Pengaturan secara umum mengenai e-commerce di Uni Eropa dituangkan dalam Europe Union Directive on Electronic Commerce $^{15}$ (EU Directive on

${ }^{15}$ EU Directive 2000/31/EC, ditandatangani pada 8 Juni 2000 oleh perwakilan negara-negara Uni
E-Commerce) mengatur mengenai hubungan para pihak dalam e-commerce (Business to Business/ B2B) termasuk terkait dengan mekanisme hukum manakah yang digunakan bagi para pihak jika terjadi permasalahan hukum yang diterapkan termasuk yurisdiksi dan peradilan mana yang berwenang mengadili dalam sengketa $e$-commerce.

Pada Pasal 3 (1) EU Directive on E-Commerce mengatur mengenai intepretasi aturan ini dalam wilayah apa saja dapat diterapkan, yaitu: ${ }^{16}$

a. Aturan-aturan dalam hukum privat internasional yang relevan diterapkan dalam setiap transaksi e-commerce.

b. Aturan mengenai hukum privat internasional ini terkait dengan IPL Rules of the country establishment of the information society service provider (ISSP) ${ }^{17}$ yang relevan diterapkan dalam transaksi e-commerce.

c. Aturan-aturan tersebut hanya berpusat pada substansi hukum, jadi hukum privat internasional tidak dapat diterapkan/dilarang jika telah diatur

Eropa dalam The European Parliament and of the Council.

16 Lilana Edward,( 2005), The New Legal Framework From E-Commerce in Europe, Oregon: Hart Publishing, hlm. 4-5.

${ }^{17}$ Pasal 2 EU Directive on E-Commerce 
dengan tegas dalam mekanisme hukum nasional para pihak.

Terkait dengan regulasi hukum internasional mengenai perlindungan hak privasi dalam kegiatan e-commerce, The Organization for Economic Cooperation and Development (OECD) yang merupakan organisasi antar-pemerintah yang terdiri dari 29 Negara anggota yang berasal dari negara-negara Uni Eropa, Amerika Serikat, Selandia Baru, Australia, dan Selandia Baru telah membuat perjanjian multilateral terkait dengan perlindungan data privasi dalam kegiatan e-commerce pada konteks global marketplace. Dimana didalam rekomendasinya memberikan kewajiban bagi negara-negara pihak untuk membuat regulasi nasional dengan prinsip-prinsip khusus mengenai proteksi atas privasi dan kebebasan individu yang berkaitan dengan data privasi konsumen daring yang terekam dalam cookies agar tidak disalahgunakan, hal ini menjadi formulasi hukum yang bersifat universal dan berlaku bagi negara-negara pihak. ${ }^{18}$

Lalu, di tingkat Uni Eropa, terdapat regulasi hukum ditingkat regional yang mengatur mengenai perlindungan data privasi dalam kegiatan e-commerce,

${ }^{18}$ Albert J. Marcella Jr. dan Carol Stucki, Op.Cit, hlm. 74 . seperti pada EU Directive on the protection of Consumers in Respect of Distance Contract, ${ }^{19}$ dalam regulasi hukum tersebut mengatur mengenai: perlindungan konsumen dari ketentuan kontrak yang tidak adil, penjualan serta jaminan atas jangka waktu penjualan, hal tersebut berkaitan dengan bagaimana harmonisasi dan pembaharuan hukum antar negara anggota Uni eropa untuk kontrak konsumen baik barang maupun jasa. $^{20}$

Selain itu, pada tahun 1995 telah diadopsi European Union Data Protection Directive (EU Data Protection Directive), yang memberikan ketentuan-ketentuan mengenai perlindungan data privasi bagi masyarakat European Union (EU), selain hal tersebut berkaitan dengan dilarangnya aliran bebas informasi antar-negara anggota EU, juga dikembangkan untuk pelaksanaan bisnis dan e-commerce.

Lebih spesifik, terkait privacy policy dalam online marketplace system di Uni Eropa diatur dalam Pasal 7EU Directive on E-Commerce dan diatur lebih spesifik dalam Pasal 5(3) The Privacy and Electronic Communication Directive 2002 (PECD), didalam aturan tersebut

\footnotetext{
${ }^{19}$ EU Directive 1997/7/EC

${ }^{20}$ Pablo Cortez, (2011), Online Dispute Resolution for Consumers in the European Union, New York: Routledge, hlm.13-14.
} 
dijelaskan bahwa teknologi cookies dalam online marketplace system telah memberi dampak yang besar terhadap pelanggaran atas data privasi konsumen daring yang sedang melakukan transaksi e-commerce, perlu ada upaya banning dari teknologi tersebut dalam segala kegiatan $e$ commerce yang sifatnya wajib untuk ditaati.

Seluruh kegiatan e-commerce termasuk perusahaan yang memproduksi produk-produk yang akan dipasarkan dalam e-commerce maupun perusahaan perbankan yang memproduksi kartu kredit bagi konsumen-konsumen yang berada di Uni Eropa diwajibkan membuat ketentuan yang jelas dan dita'ati para pihak melalui privacy policy yang sesuai dengan standar dari $E U$ Directive tersebut. Didalam privacy policy tersebut harus bersifat jujur dan memuat informasi yang komprehensif, baik tentang tujuan hingga proses dari pengolahan data daring tersebut, sehingga hak-hak privasi dari konsumen daring tidak terlanggar dalam kegiatan $e$ commerce tersebut. ${ }^{21}$

Selain berlaku di tingkat regional EU, pelbagai regulasi yang berkaitan dengan privacy policy dalam online marketplace system juga diterapkan

\footnotetext{
${ }^{21}$ Ibid, h. 56-57.
}

didalam ketentuan hukum nasional beberapa negara di Uni Eropa, tidak semua negara-negara Uni Eropa akan dibahas didalam pembahasan ini, pembahasan dikhususkan kepada negara-negara yang telah established dalam pembuatan kebijakan privacy policy dalam online marketplace system, negara-negara tersebut adalah: Prancis, Jerman, Britania Raya. $^{22}$

Prancis

Bagi Negara Prancis, telah memiliki regulasi hukum yang telah lama diterapkan pada tahun 1978 berkaitan dengan data processing, data files, and individual liberties (relative it l'infonnatique, aux fichiers et aux libertes), regulasi hukum tersebut kemudian terdapat perubahan-perubahan yang menyesuaikan ketentuan dalam EU Directive.

Pasal 1 dari Undang-Undang tersebut menyatakan bahwa" Computers must be at the service of each citizen. Their development must occur in the framework of international co-operation. It must cause no damage or loss to either human identity, human rights, right of privacy, or to public and individual liberties". pada regulasi hukum tersebut secara tersirat menyatakan bahwa

\footnotetext{
${ }^{22}$ Gerald Spindler, (2002), E-Commerce In Europe and USA, Berlin: Springer-Verlag, hlm.93-296.
} 
Pemerintah Negara Prancis menjamin penggunaan teknologi komputer khususnya internet sesuai dengan mekanisme hukum internasional (baik yang berlaku di tingkat regional Uni Eropa maupun internasional) dan tanpa melanggar HAM, hak privasi, dan kebebasan individu seseorang.

Lembaga Negara yang memiliki otoritas untuk mengkontrol agar hak privasi dapat terpenuhi dengan dibentuknya "Commission Nationale de l'Infonnatique et des Libertes" selanjutnya disingkat CNIL. Pada Pasal 19, pengaturan mengenai data privasi ini digunakan dalam sektor, yaitu: identitas pemilik data, tujuan dari pemrosesan data, penerima data, pengelolaan data di wilayah-wilayah manakah yang diperkenankan, alih pihak data, katagori siapa-siapakah yang berhak mengakses data privasi, dsb.

Walaupun dapat dilihat masih umum, namun regulasi hukum tersebut berlaku terhadap semua sektor, salah satunya adalah sektor e-commerce, dan segala perubahannya mengikuti ketentuan yang diterapkan di negara-negara Uni Eropa sehingga tidak ada hambatan bagi Negara Prancis untuk melindungi konsumen daring yang melakukan transaksi e-commerce agar tidak terlanggar hak privasinya pada online marketplace system.

Jerman

Negara Jerman telah memiliki regulasi hukum yang berkaitan dengan data privasi dalam transaksi e-commerce yang merupakan penerapan langsung dari Directive 97/7/EC dari Kesepakatan parlemen-parlemen di Uni Eropa terkait dengan perlindungan konsumen yang berkaitan dengan kontrak, hal tersebut kemudian dituangkan dalam Distance Contract Act.

Dalam regulasi hukum tersebut menjelaskan secara komprehensif mengenai kewajiban dan tanggung jawab dari pelaku usaha, khususnya terakit proteksi kepada status perlindungan konsumen yang ditempatkan sangat baik, yang juga mengedepankan prinsip favourable. Selain itu, juga berlaku integrasi standart privacy policy pada online marketplace system yang disesuaikan dengan Pasal 2 Distance Contract Act, sehingga memastikan baik penyedia jasa e-commerce dan konsumen daring melakukan perikatan dengan baik dan menjamin terpenuhinya perlindungan data privasi. 
Britania Raya

Sebagai gabungan dari negaranegara Inggris daratan, Britania Raya yang terdiri dari Inggris, Wales, dan Irlandia memiliki regulasi hukum yang berkaitan dengan data privasi, hal tersebut dituangkan dalam The Data Protection Act 1998, memuat ketentuan mengenai informasi pribadi didalam regulasi hukum nasional yang diatur dibawah regulasi English Law. Dapat diringkas, bahwa hak privasi dalam aspek e-commerce mengatur mengenai:

a. Proses yang adil dan sesuai kaidah hukum (termasuk hal-hal yang berkaitan dengan informasi sensitif konsumen daring)

b. Proses dan tujuan khusus pengelolaan data privasi

c. Keadaan, relevansi, dan hal-hal yang tidak diperkenankan terkait dengan pengelolaan data privasi.

d. data dapat dikumpulkan sejauh dari kesesuaian tujuan apa data tersebut dikumpulkan/ bukan untuk tujuan profit.

e. Menghormati hak-hak setiap individu yang berkaitan dengan informasi data pribadi dan preferensi pencarian didalam kegiatan e-commerce.

f. Melindungi dari akses terhadap data pribadi yang tidak diperkenankan g. Dapat menerima konsekwensi pengaturan diluar yurisdiksi hukum yang ditentukan oleh Uni Eropa asalkan tidak bertentangan dengan aturan-aturan di Britania Raya mengenai perlindungan data privasi

Amerika Serikat

Sama halnya dengan Negaranegara di Uni Eropa, pengaturan mengenai perlindungan data privasi di negara Amerika Serikat dibahas secara detail, dimana pendekatan yang dipakai oleh pemerintah Amerika Serikat mencegah secara spesifik pelang dalam aran privasi dan data-data sensitf, hal ini berlaku baik di negara-negara bagian maupun negara federal.

Terkait dengan perlindungan data privasi terhadap konsumen diatur dalam Federal Trade Commision Act 2010 (FTC Act 2010) yang dilaporkan dalam 'Protecting Consumer Privacy in a Era of Rapid Change; A Proposed Framework for Business and Policymaker. ${ }^{23}$

Dalam FTC Act 2010 dapat dilihat terkait dengan kerangka kerja hubungan transaksi elektronik dari penyedia $e$ commerce dan konsumen daring, yaitu:

\footnotetext{
${ }^{23}$ Andrew Sewin, et.al, (2012), Data protection and Privacy, London: Sweet \& Maxwell, hlm. 633-634.
} 
a. Menerapkan dan membangun prinsip perlindungan data privasi dalam setiap praktik bisnis.

b. Menyediakan ruang yang luas bagi konsumen untuk meghormati perlindungan data privasi yang dipunya termasuk dalam rangka pemanfaatan kepentingan komersial dari data privasi itu sendiri.

c. Membuat praktik pemanfaatan data privasi lebih transparan agar tidak ada para pihak yang terciderai hak-nya.

d. Mengambil langkah edukatif kepada konsumen terkait praktik penggunaan data privasi untuk kepentingan komersial dengan pilihan-pilihan yang ada.

e. Penegakkan hukum bagi pelanggar FTC Act 2010 tersebut, pemerintah Amerika memiliki badan-badan untuk perlindungan konsumen, yaitu: (i) US Departement of Commerce, White House/ sub bagian Kepresidenan AS (National Strategy of Trusted Identities in Cyberspace Initiative) yang bekerjasama dengan kekuatan sipil lainnya untuk mendorong privasi, keamanan, dan perlindungan data sensitif dalam transaksi online.

Jepang

Negara Jepang merupakan negara yang sangat prospektif terkait dengan perkembangan e-commerce dibandingkan dengan negara-negara lainnya Asia, dalam pengembangan dari sistem perlindungan data privasi pada e-commerce di Negara Jepang, sekitar tahun 2000 Pemerintah Federal Jepang membuat regulasi hukum mengenai data privasi yang sedikit banyak mengadopsi ketentuan hukum yang berlaku di Amerika Serikat dan Uni Eropa. Pengembangan atas undangundang terkait perlindungan data privasi didorong oleh Keidanren, yang merupakan representative body yang khusus mengatur masalah industri dan perdagangan, sehingga pada tahun 2003 telah disahkan dan mulai berlaku established pada 2005.

Data Protection Act di Jepang yang didorong oleh Keidanren adalah dalam rangka penyesuaian mekanisme perdagangan internasional seperti yang terdapat di Uni Eropa maupun regulasi hukum perdagangan Amerika Serikat, atau juga sesuai dengan ketentuan Safe Harbour Agreement antara Uni Eropa dengan Amerika Serikat. Upaya membuat rezim hukum perlindungan data privasi yang berlaku bagi perusahaan Jepang yang telah masuk dalam persaingan perdagangan di Uni Eropa, dengan dasar kepentingan tersebut maka disetujui usulan 
dari Keidanren terkait dengan Data Protection Act tersebut. ${ }^{24}$

Prinsip-prinsip yang Dibangun Dalam Privacy Policy

Simon Ginkhaef ${ }^{25}$ memberikan petunjuk terkait dengan prinsip-prinsip yang dibangun dalam privacy policy, bahwa keberadaan privacy policy pada awal digunakannya e-commerce menjadi petunjuk bagi penyedia online marketplace system untuk tidak melanggarnya karena hal tersebut menjadi dasar bagi itikad yang baik antar para pihak dalam melakukan aktivitas e-commerce, yaitu:

a. Diwajibkannya sistem pencatatan data yang sifatnya sangat rahasia.

b. Bagi data privasi yang telah tercatat, harus ada upaya yang diberikan bagi pemilik data untuk mengetahui bagaimana data privasi tersebut digunakan

c. Bagi pemilik data privasi, harus tersedia upaya yang diberikan untuk mencegah dari penggunaan data privasi yang tidak sesuai/bertentangan dengan persetujuan yang disepakati dalam privacy policy tersebut.

\footnotetext{
${ }^{24}$ Graham Graenlaf,( 2014), Asian Data Privacy Law: Trade and Human Right Perspectives, Oxford: Oxford Publisher, hlm. 317-318.

${ }^{25}$ Simon Ginkhaef, Op.Cit, hlm. 594.
}

d. Harus tersedia cara bagi pemilik data pribadi untuk mengubah dan memperbaiki identitasnya.

e. Setiap pihak yang telah melanggar ketentuan privacy policy dengan mengumpulkan, menyalahgunakan, dan menyebarluaskan data privasi harus mengambil tindakan-tindakan pemulihan, ganti rugi, dan menjaganya kembali di kemudian hari.

Prinsip-prinsip tersebut menjadi pegangan baik bagi konsumen maupun penyedia e-commerce dan penyedia online marketplace system untuk memenuhi ketentuan dalam setiap awal melakukan kegiatan e-commerce, harus dipakati privacy policy yang menjadi aturan dalam hubungan ekonomi tersebut.

Tujuan Pengaturan Privacy Policy

Tujuan paling penting dari privacy policy dalam kegiatan e-commerce adalah selain memberikan kepastian hukum kepada konsumen terhadap informasi pribadi yang telah di-input dan atau preferensi yang dilakukan dalam kegiatan transaksi elektronik tersebut tidak disalahgunakan dan dijaga kerahasiaannya, karena hal tersebut selain berkaitan dengan hak asasi manusia konsumen, juga berkaitan dengan upaya dari penyedia jasa e-commerce maupun penyedia online marketplace system untuk menghindari 
pelanggaran atas rasa aman dan nyaman serta dignity dari konsumen itu sendiri.

Selain term and condition yang menjadi petunjuk bagi konsumen pada awal melakukan kegiatan e-commerce, konsumen juga diharuskan mempelajari privacy policy dimana hal tersebut bertujuan preventif perlindungan atas pelanggaran privasi konsumen yang diakibatkan penggunaan teknologi cookies pada online marketplace system. Apabila dirasa privacy policy dari konsumen rentan, maka disarankan konsumen $e$ commerce tidak menggunakan media tersebut.

\section{Manfaat Pengaturan Privacy Policy}

Manfaat yang dicapai dalam pengaturan privacy policy pada kegiatan $e$ commerce apabila dijalankan dan ditaati dengan baik oleh kedua belah pihak, yaitu:

a) Meningkatkan rasa aman dan kepercayaan antara konsumen daring dan penyedia $e$-commerce.

b) Terlindunginya hak privasi bagi konsumen daring dalam kegiatan $e$ commerce yang dilakukan.

c) Terciptanya iklim persaingan usaha yang sehat pada setiap aktivitas transaksi elektronik.

d) Terdapat penyelesaian hukum yang tepat sesuai yang disepakati pada privacy policy jika dikemudian hari konsumen darig terlanggar hak-hak privasinya.

Pelanggaran Privacy Policy Pada Online Marketplace System di Indonesia

Terkait dengan pelanggaran hak privasi yang dialami oleh konsumen pada online marketplace system, dibutuhkan langkah preventif/ kehati-hatian dari konsumen untuk mencantumkan data-data privasinya termasuk hobby dan kecenderungan, karena ketika hal tersebut telah ditabulasi oleh perusahaan, maka yang terjadi hak privasi dari konsumen sendiri yang terlanggar. Selama ini pengaduan masyarakat yang dilaporkan pada direktorat e-business, Kemenkominfo mayoritas berkaitan dengan ketidak sesuaian barang yang dipesan dengan barang yang diterima, untuk kasus terkait hak privasi belum ada laporan pengaduan.

Laporan pada tahun 2013 oleh United Nations Conference on Trade and Development (UNCTAD) mencatat bahwa, sebanyak 2.100 kejadian yang telah memakan banyak kerugian pada data privasi dengan taksiran 822 juta data privasi telah terekam dalam kegiatan $e$ commerce dan telah dikumpulkann dalam online marketplace system. Hampir sekitar 152 juta nama, identitas konsumen, enkripsi pasword, nomor kartu debit dan kredit, serta informasi yang berkaitan 
dengan apa yang konsumen harap untuk dibeli/permintaan konsumen telah direkam. Jika diprosentase, pelaku yang berasal dari sektor bisnis sekitar 53\% dari total pihak yang melakukan pelanggaran data privasi, dan jelas tujuannya untuk kepentingan bisnis, data privasi yang sering di-collect adalah pasword akun, nama pengguna akun, dan percakapan di email. $^{26}$

Salah satu kasus yang dipublikasi oleh UNCTAD terkait dengan pelanggaran data privasi dalam kegiatan e-commerce pada tahun 2015 di Afrika Timur. Dimana terdapat penyedia e-commerce melakukan pengumpulan data privasi pada mesin pembayaran otomatis yaitu nomor dan identitas pengguna kartu kredit tanpa sepengetahuan pemilik data dengan memanfaatkan peralatan Skimming dengan tujuan mendatangkan konsumen daring lebih banyak.

Begitu pula yang terjadi pada $3 G$ Direct Pay yang bergerak pada payment gateway e-commerce, penyedia jasa pembayaran tersebut telah merekam lebih ribuan data privasi pelanggan yang

26 UNCTAD, (2015), Report no. TD/B/C.II/EM.5/2: Trade and Development Board; Investment, Enterprise, and Development Commission Expert Meeting on Cyberlaws and Regulations for Enhancing E-Commerce, Geneva: United Nations, hlm. 10-11. didapatkan dari 300 perusahaan tur dan travel yang ada di Afrika Timur, karena data privasi konsumen daring tersebut dicuri, maka bisa terjadi pembayaran transaksi tanpa persetujuan dan hal tersebut jelas selain pelanggaran hak privasi juga dapat dikategorikan cybercrime, maka dari itu $3 G$ Direct Pay membuat fitur keamanan enkripsi "end-toend" untuk menanggulangi peretasan atas data privasi tersebut dan terus dimonitor secara berkala. $^{27}$

Sementara itu, tidak dapat diungkap kasus secara eksplisit yang menangani aduan pelanggaran hak privasi bagi konsumen daring di Indonesia. Akan tetapi, jika ditelusuri dapat dikatakan bahwa hampir sebagian besar situs-situs di Indonesia mengumpulkan data privasi konsumen, bahkan ada beberapa situs jualbeli online di Indonesia yang tidak mencantumkan ketentuan privacy policy dan mengungkapkan dengan gamblang profiling calon pembeli dan memberikan gambaran calon pembeli kepada penjual barang tanpa izin dari pembeli itu sendiri dan hanya memuat terkait tata cara pembayaran saja, situs yang dimaksud adalah glodokshop.com, hal tersebut membuktikan bahwa posisi dari konsumen

${ }^{27}$ Ibid, hlm. 11. 
daring amatlah rentan terhadap penyalahgunaan data pribadi untuk kepentingan komersial. $^{28}$

Selain itu, terdapat beberapa situs lain yang mencantumkan perlindungan informasi pribadi baik yang diungkapakn secara langsung maupun dimuat didalam ketentuan kebijakan privasi, kemanan belanja, ketentuan layanan, legal notice, hingga sampai kepada perlindungan hukumnya, situs-situs tersebut seperti: geowebindonesia.com, lipposhop.com, link.net, astaga.com. namun, ada juga situs yang menyatakan tidak dapat dituntut secara hukum atas kelalaian yang diakibatkan baik secara langsung maupun tidak langsung dan menimbulkan kerugian, kesalahan, penghapusan, interupsi, pelanggaran virus, penghilangan file atau email, dan kerugian kehilangan privasi didalam "pemberitahuannya", hal tersebut dilakukan oleh BolehMail.com. ${ }^{29}$

\section{Kesimpulan}

Dalam rangka melindungi hak privasi agar tidak terlanggar oleh penyedia e-commerce maupun penyedia online marketplace system, maka dimungkinkan adanya upaya hukum yang diakses oleh

\footnotetext{
${ }^{28}$ Suradji, et.al, (2005), Penelitian Tentang Perlindungan Hukum Data Digital, Jakarta: Badan Pembina Hukum Depkumham RI, hlm. 107-108.

${ }^{29}$ Ibid, hlm. 108-109
}

konsumen daring yang diatur dalam mekanisme hukum internasional.

Mekanisme penyelesaian sengketa terkait e-commerce (Online Dispute Resolution/ODR) lebih spesifik mengenai pelanggaran atas data privasi merupakan perpaduan penyelesaian antara IT dan penyelesaian diluar sengketa (alternative dispute resolution), Pablo Cortez menyatakan bahwa Mekanisme penyelesaian sengketa terkait e-commerce (Online Dispute Resolution/ ODR) lebih spesifik mengenai pelanggaran atas data privasi merupakan perpaduan penyelesaian antara IT dan penyelesaian diluar sengketa (alternative dispute resolution), Pablo Cortez menyatakan bahwa Metode penyelesaian sengketa dapat terpenuhi dengan ketentuan-ketentuan IT atau dalam konteks ini yang menjadi costumary dalam penyelesaian sengketa $e$-commerce, hal ini termasuk penunjuk netral, proses penyusunan identitas, mendengarkan masukkan oral dari para pihak, diskusi hingga keputusan yang bersifat mengikat. ODR berusaha mensinergikan antara penyelesaian diluar peradilan maupun pendekatan-pendekatan yang sesuai dengan kaidah IT, bahwa upaya hukum 
tersebut merupakan perkembangan yang marak terjadi dewasa ini. ${ }^{30}$

Upaya hukum yang dapat ditempuh oleh konsumen daring terkait pelanggaran data privasi dapat dilihat dari dua proses, yaitu proses ajudikatif (litigasi dan arbitrase) dan proses konsensus (mediasi dan negosiasi), UNCTAD dalam $E$ Commerce and Development Report 2003 memberikan gambaran mengenai unsurunsur dalam penyelesaian secara ajudikatif dan konsensus tersebut, yaitu: ${ }^{31}$

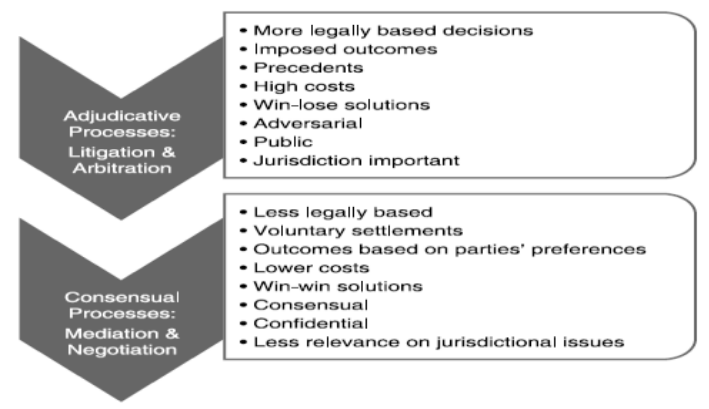

Gambar 1: UNCTAD, "E-Commerce and Development Report 2003 Chapter 7, Online Dispute Resolution: ECommerce and Beyond", hlm. 178

Selain itu, terkait dengan hukum yang tersedia bagi korban pelanggaran hak privasi sesuai regulasi hukum Negara Indonesia berdasarkan UU Nomor 18 Tahun 2008 tentang ITE dan PP Nomor 28 Tahun 2012 tentang PSTE dapat melakukan gugatan kerugian secara perdata, artinya bahwa mekanisme hukum menuntut ganti rugi dari pengguna daring kepada penyedia e-commerce yang baru

\footnotetext{
${ }^{30}$ Pablo Cortez, Op.Cit, hlm. 52-53

${ }^{31}$ Ibid
}

tersedia mekanisme meminta ganti rugi keperdataan. Padahal pelanggaran data privasi ini luas sifatnya dan tidak terbatas pada unsur keperdataan semata, maka perlu ada regulasi hukum yang lebih spesifik dan memperluas upaya hukum yang dilakukan bagi konsumen yang terlanggar hak privasinya.

\section{E. Daftar Pustaka}

Buku dan Jurnal

Abu Bakar Munir dan Siti Hajar Mohd. Yasin, (2002), Privacy and Data Protection, Selangor: Thomson, Sweet and Maxell Asia.

Colin J. Bennet, (2008), The Privacy Advocates: Resisting the Spread of Surveillance, Cambridge: The MIT Press.

Daniel J. Solove, (2004), The Digital Person, Technology and Privay in the Information Age, West Group Publication, New York: New York University Press.

Edmond Makarim, (2013), Challenges to National e-Authentication, International Seminar on Cyberlaw, Lembaga Kajian Hukum dan Teknologi, Denpasar: Fakultas Hukum Universitas Indonesia.

Inge Graef, (2015), Market Definition and Market Power in Data: The Case of Online Platforms, World Competition 38, No.4, Amsterdam: Kluwer Law International.

Jovan Kurbalija, (2014), (6 ${ }^{\text {th }}$ Edition), an Introduction to Internet Governance, Jenewa: Diplo Foundation

Masitoh Indriani, Praktek Surveillance dan Unlawful Interception sebagai Pelanggaran terhadap Hak atas 
Privasi, R. Herlambang Perdana Wiratraman et.al., (2015), Kebebasan Berekspresi di Indonesia: Hukum, Dinamika, Masalah dan Tantangannya, Jakarta: Elsam.

Peter Mahmud Marzuki, (2008), Penelitian Hukum, Jakarta: Kencana Prenada Media Group.

Shinta Dewi, (2009), Perlindungan Privasi Atas Informasi Pribadi Dalam ECommerce Menurut Hukum Internasional, Widya Padjajaran: Bandung,

Sudikno Mertokusumo, (2007), (Cet. Ke-5), Penemuan Hukum: Sebuah Pengantar, Yogyakarta: Liberty.

Tim Privacy International dan ELSAM, (2015), Privasi 101: Panduan Memahami Privasi, Perlindungan Data dan Surveilans Komunikasi, Jakarta: Elsam.

W. Kuan Hon, Christopher Milliard, Ian Walden, (2011), The Problem of 'Personal Data' in Cloud Computing - What Information is Regulated? (The Cloud of Unknowing, Part 1)", International Data Privacy Law (2011) 1 (4): 211-228, Queen Mary University of London, School of Law, Legal Studies Research Paper No.75/2011.

Wahyudi Djafar dan Asep Komarudin, (2014), Perlindungan Privasi di Internet: Beberapa Penjelasan Kunci, Seri Internet dan HAM, Jakarta: ELSAM.

Perundang-undangan dan Konvensi Internasional

Undang-undang Nomor 23 Tahun 2006 tentang Administrasi Kependudukan

Undang-undang Nomor 11 Tahun 2008 tentang Informasi dan Transaksi Elektronik
Undang-undang Nomor 14 Tahun 2008 tentang Keterbukaan Informasi Publik

Peraturan Pemerintah No 82 Tahun 2012 tentang Penyelenggaran Sistem Transaksi Elektronik

Deklarasi Universal tentang Hak Asasi Manusia (Universal Declaration of Human Rights, 1948)

Kovenan Internasional tentang Hak Sipil dan Politik (International Covenant on Civil and Political Rights, 1966)

Internet

Simon Kemp, (2015), Digital, Social, Mobile in 2015, We Are Social, We Are Social, http://wearesocial.sg/blog/2015/01/di gital-social-mobile-2015/ [Akses, 5 Juni 2017]

Enrico Lukman, (2015), The latest numbers on web, mobile, and social media in Indonesia (INFOGRAPHIC),https://www.techi nasia.com/indonesia-web-mobiledata-start-2015, [akses pada 3 Maret 2017].

Resty Woro Yuniar, (2015), What makes e-Commerce Work in Indonesia, The Wall

Street Journal,http://blogs.wsj.com/indones iarealtime/2015/03/03/what-makese-commerce-work-in-indonesia/, [akses pada 3 Maret 2017]. 